Pacific Journal of Mathematics

ON THE STONE-WEIERSTRASS APPROXIMATION THEOREM
FOR VALUED FIELDS 


\title{
ON THE STONE-WEIERSTRASS APPROXIMATION THEOREM FOR VALUED FIELDS
}

\author{
David G. CANTOR
}

\begin{abstract}
Let $X$ be a compact topological space, $L$ a non-Archimedean rank 1 valued field and $\mathfrak{F}$ a uniformly closed $L$-algebra of $L$-valued continuous functions on $X$. Kaplansky has shown that if $\mathfrak{F}$ separates the points of $X$, then either $\mathfrak{F}$ consists of all $L$-valued continuous functions on $X$ or else all of them which vanish on one point in $X$. In this paper analogous results are obtained, in the case that a group of transformations acts both on $X$ and $L$, for the invariant $L$-valued continuous functions on $X$.
\end{abstract}

If $L$ and $K$ are fields such that $L \subset K$ and $L / K$ is normal, we let Aut $(L / K)$ denote the group of automorphisms of $L$ which leave every element of $K$ fixed, and we give Aut $(L / K)$ the Krull topology; a basis for the open neighborhoods of the identity of Aut $(L / K)$ is given by subgroups of the form

$$
\left\{\sigma \in \operatorname{Aut}(L / K): \sigma x=x \text { if } x \in L_{1}\right\}
$$

where $L_{1}$ is a finite extension of $K$ contained in $L$.

Now suppose that $L$ is a non-Archimedean field with a (multiplicative) rank 1 valuation, denoted | | [1]. Suppose $K$ is a subfield of $L$ such that $L / K$ is both normal and separable. Denote by $L_{c}$ a completion of $L$ and let $K^{\prime}$ be the closure of $K$ in $L_{c}$. Put $L^{\prime}=L K^{\prime}$ (the composite field generated by $L$ and $K^{\prime}$ in $L_{c}$ ) and note that $K$ is dense in $K^{\prime}$. It is clear that $L^{\prime} / K^{\prime}$ is normal and separable. If $\sigma \in$ Aut $\left(L^{\prime} \mid K^{\prime}\right)$, then, since $K^{\prime}$ is complete, $|\sigma x|=|x|$ for each $x \in L^{\prime}$ so that $\sigma$ is a continuous map of $L^{\prime}$ onto itself; furthermore the restriction of $\sigma$ to $L,\left.\sigma\right|_{L} \in \operatorname{Aut}(L / K)$. Finally suppose that $X$ is a compact topological space for which there exists a continuous map $(\sigma, x) \rightarrow \sigma x$ of Aut $\left(L^{\prime} / K^{\prime}\right) \times X \rightarrow X$ satisfying $\sigma_{1}\left(\sigma_{2} x\right)=\left(\sigma_{1} \sigma_{2}\right) x$ if $\sigma_{1}, \sigma_{2} \in \operatorname{Aut}\left(L^{\prime} / K^{\prime}\right)$, $x \in X$ and satisfying $e x=x$ if $e$ is the identity of Aut $\left(L^{\prime} / K^{\prime}\right)$ and $x \in X$. It is immediate that if $\sigma \in \operatorname{Aut}\left(L^{\prime} / K^{\prime}\right)$ then the map $x \rightarrow \sigma x$ of $X \rightarrow X$ is a homeomorphism of $X$. We shall call a set $Y \subset X$ invariant if Aut $\left(L^{\prime} / K^{\prime}\right) Y=Y$. Denote by $C_{L / K}(X)$ the set of $L$-valued continuous functions $f$ on $X$ satisfying $f(\sigma x)=\sigma f(x)$ for all $x \in X$ and $\sigma \in \operatorname{Aut}\left(L^{\prime} / K^{\prime}\right) ; C_{L / K}(X)$ is a $K$-algebra. If $E$ is any valued field, denote by $C_{E}(X)$ the continuous $E$-valued functions on $X$ and give $C_{E}(X)$ the sup-norm topology. Clearly $C_{L}(X) \supset C_{L / K}(X) \supset C_{K}(X)$.

THEOREM 1. Suppose $\mathfrak{F}$ is a closed (in the sup-norm) K-sub- 
algebra of $C_{L / K}(X)$ which separates the points of $X$ (i.e. if $x, y \in X$ and $x \neq y$, there exists $f \in \mathfrak{F}$ such that $f(x) \neq f(y))$. Then either $\widetilde{F}=C_{L / K}(X)$ or there exists $x_{0} \in X$ such that

$$
\mathfrak{F}=\left\{f \in C_{L / K}(X): f\left(x_{0}\right)=0\right\} \text {. }
$$

In the latter case the set $\left\{x_{0}\right\}$ is invariant.

Proof. Let $\widetilde{F}^{\prime}$ be the uniform closure of the $K^{\prime}$ algebra of functions generated by $\widetilde{F}$ in $C_{L^{\prime}}(X)$; since $K$ is dense in $K^{\prime}$, $₹$ is dense in $\mathfrak{F}^{\prime}$ and hence it suffices to prove that $\mathfrak{F}^{\prime}=C_{L^{\prime} \mid K^{\prime}}(X)$ or that $\mathfrak{F}^{\prime}=$ $\left\{f \in C_{L^{\prime} / K^{\prime}}(X): f\left(x_{0}\right)=0\right\}$. Thus we may assume without loss of generality that $K=K^{\prime}$ and $L=L^{\prime}$. We assume first that for each $x \in X$, there exists $f \in \widetilde{F}$ such that $f(x) \neq 0$

Lemma 2. Assuming the hypotheses of Theorem 1, if $x_{0} \in X$ and $g \in C_{L / \mathbb{K}}(X)$, there exists $f \in \mathfrak{F}$ such that $f\left(x_{0}\right)=g\left(x_{0}\right)$.

Proof. Put $L_{1}=\left\{h\left(x_{0}\right): h \in \widetilde{F}\right\}$; clearly $L_{1}$ is a $K$-subalgebra of $L$ containing a nonzero element of $L$. Suppose $c \in L_{1}$ and $c \neq 0 ; c$ satisfies a polynomial equation $\sum_{i=0}^{n} a_{i} c^{i}=0$, where the $a_{i} \in K$ and $a_{0} \neq 0$. Then $a_{0} \in L_{1}$ and hence $K=K a_{0} \subset L_{1}$. It follows that $L_{1}$ is a subfield of $L$. Put

$$
H=\left\{\sigma \in \operatorname{Aut}(L / K): \sigma x_{0}=x_{0}\right\} ;
$$

$H$ is a closed subgroup of Aut $(L / K)$ which fixes every element of $L_{1}$ and also fixes $g\left(x_{0}\right)$. Now if $\sigma \in \operatorname{Aut}(L / K)-H$, then $x_{0} \neq \sigma x_{0}$, and there exists $h \in \mathfrak{F}$ such that $h\left(x_{0}\right) \neq h\left(\sigma x_{0}\right)$ or $h\left(x_{0}\right) \neq \sigma h\left(x_{0}\right)$. Equivalently, if $\sigma \in \operatorname{Aut}(L / K)$ fixes every element of $L_{1}$, then $\sigma \in H$. Thus $L_{1}$ is the fixed field of the closed subgroup $H$. As $H$ fixes $g\left(x_{0}\right)$, we have $g\left(x_{0}\right) \in L_{1}$, and there exists $f \in \widetilde{F}$ such that $f\left(x_{0}\right)=g\left(x_{0}\right)$.

LEMMA 3. Assuming the hypotheses of Theorem 1, $X$ is totally disconnected.

Proof. Since $\mathfrak{F}$ separates points, $X$ is Hausdorff. Now take $x_{0} \in X$ and an open neighborhood $U$ of $x_{0}$. For each $y \notin U$, there exists $f_{y} \in \mathfrak{F}$ such that $f_{y}\left(x_{0}\right) \neq f_{y}(y)$. Put $\varepsilon_{y}=\left|f_{y}\left(x_{0}\right)-f_{y}(y)\right|$, and let

$$
U_{y}=\left\{x \in X:\left|f_{y}(x)-f_{y}\left(x_{0}\right)\right|<\varepsilon_{y} / 2\right\}
$$

and

$$
V_{y}=\left\{x \in X:\left|f_{y}(x)-f_{y}(y)\right|<\varepsilon_{y} / 2\right\} ;
$$

$U_{y}$ and $V_{y}$ are disjoint open and closed subsets of $X$ with $x_{0} \in U_{y}$. 
The $V_{y}$ cover the compact set $X-U$ and hence there exists a finite number, say $V_{y_{1}}, V_{y_{2}}, \cdots, V_{y_{n}}$ whose union contains $X-U$. Then $\bigcap_{i=1}^{n} U_{y_{i}}$ is an open and closed neighborhood of $x$ contained in $U$.

Lemma 4. Assuming the hypotheses of Theorem 1, suppose $V$ is an open and closed invariant subset of $X$. Then the characteristic function of $V$ is in $\mathfrak{F}$.

Proof. By the Kaplansky-Stone-Weierstrass Theorem [2] and Lemma 3, the characteristic function of $V$ is in the uniform closure of the $L$-subalgebra of $C_{L}(X)$ generated by $\mathfrak{F}$. Hence, if $\varepsilon>0$, there exists $f \in C_{L}(X)$ such that $f=\sum_{i=1}^{m} a_{i} h_{i}$ where the $a_{i} \in L$ and the $h_{i} \in \mathfrak{F}$ and such that $|f(y)-1|<\varepsilon$ if $y \in V$ while $|f(y)|<\varepsilon$ if $y \notin V$. Let $L_{1} \subset L$ be the smallest normal extension field of $K$ containing all of the $a_{i} ; L_{1}$ is a finite algebraic extension of $K$ and hence Aut $\left(L_{1} / K\right)$ is finite. As Aut $\left(L_{1} / K\right)$ is a homomorphic image of Aut $(L / K)$, there exist representatives $\sigma_{1}, \sigma_{\varepsilon}, \cdots, \sigma_{n}$ of $\operatorname{Aut}\left(L_{1} / K\right)$ in Aut $(L / K)$ and the set of restrictions $\left\{\left.\sigma_{i}\right|_{L_{1}}: 1 \leq i \leq n\right\}$ is $\operatorname{Aut}\left(L_{\mathrm{l}} / K\right)$. If $\sigma \in \operatorname{Aut}(L / K)$, put $f^{\sigma}=\sum_{i=1}^{m}\left(\sigma a_{i}\right) h_{i}$. Then if $y \in X$,

$$
\begin{aligned}
f^{\sigma}(y) & =\sum_{i=1}^{m}\left(\sigma a_{i}\right) h_{i}\left(\sigma \sigma^{-1} y\right) \\
& =\sigma\left(\sum_{i=1}^{m} a_{i} h_{i}\left(\sigma^{-1} y\right)\right) \\
& =\sigma f\left(\sigma^{-1} y\right) .
\end{aligned}
$$

As $\sigma^{-1} V=V,\left|f^{\sigma}(y)-1\right|<\varepsilon$ if $y \in V$, while $\left|f^{\sigma}(y)\right|<\varepsilon$ if $y \notin V$. Put $g=\prod_{i=1}^{n} f^{\sigma_{i}}$; then $g \in \widetilde{F}$ and $|g(y)-1|<\varepsilon$ if $y \in V$ while $|g(y)|<\varepsilon$ if $y \notin V$. Thus letting $\varepsilon \rightarrow 0$, we see that the characteristic function of $V$ is in $\mathfrak{F}$.

Proof of Theorem 1 (concluded). Suppose $f \in C_{L / K}(X)$ and $\varepsilon>0$. For each $x \in X$, there exists by Lemma $2, g_{x} \in \mathfrak{F}$ such that $g_{x}(x)=f(x)$. Let $U_{x}$ be an open and closed neighborhood of $x$ such that $\mid g_{x}(y)-$ $f(y) \mid<\varepsilon$ whenever $y \in U_{x}$. Put $V_{x}=\operatorname{Aut}(L / K) U_{x}$; clearly $V_{x}$ is invariant. As $V_{x}$ is the union of the open sets $\sigma U_{x}, \sigma \in \operatorname{Aut}(L / K), V_{x}$ is open, and since it is the continuous image of the compact set $\operatorname{Aut}(L / K) \times U_{x}$, it is compact. If $y \in V_{x}$, there exists $\sigma \in \operatorname{Aut}(L / K)$ such that $\sigma y \in U_{x}$. Then

$$
\begin{aligned}
\left|g_{x}(y)-f(y)\right| & =\left|\sigma\left(g_{x}(y)-f(y)\right)\right| \\
& =\left|g_{x}(\sigma y)-f(\sigma y)\right|<\varepsilon .
\end{aligned}
$$

The $V_{x}$ are open sets which cover $X$. Hence a finite number, say $V_{x_{1}}, V_{x_{2}}, \cdots, V_{x_{n}}$ cover $X$. Put $D_{1}=V_{x_{1}}$ and for $2 \leq i \leq n$, put 


$$
D_{i}=V_{x_{i}}-\bigcup_{j=1}^{i-1} V_{x_{j}} .
$$

Each $D_{i}$ is open and closed, and invariant; hence by Lemma 4 , the characteristic function $h_{i}$ of $D_{i}$ is in $\mathfrak{F}$. In addition the $D_{i}$ are disjoint and $\bigcup_{i=1}^{n} D_{i}=X$. Now put

$$
g=\sum_{i=1}^{n} h_{i} g_{x_{i}},
$$

so that $g \in \mathfrak{F}$. If $y \in X$, then there exists $j$ such that $y \in D_{j} \subset V_{x_{j}}$; then $g(y)=g_{x_{y}}(y)$. As $\left|g_{x_{j}}(y)-f(y)\right|<\varepsilon,|g(y)-f(y)|<\varepsilon$. Letting $\varepsilon \rightarrow 0$ shows that $f \in \mathfrak{F}$. Finally, if there exists $x_{0} \in X$ such that $f\left(x_{0}\right)=0$ for all $f \in \mathfrak{F}$, let $\mathfrak{F}_{1}$ be the $K$-algebra obtained from $\mathfrak{F}$ by adjoining the $K$-valued constant functions. Then if $g \in C_{L / K}(X)$ satisfies $g\left(x_{0}\right)=0$, and $\varepsilon>0$, there exists by what we have proved $f_{1} \in \mathscr{F}_{1}$ such that $\left|f_{1}(x)-f(x)\right|<\varepsilon$ for all $x \in X$. Then $f_{1}=f+a$, where $f \in \mathfrak{F}$ and $a \in K$. Now $|a|=\left|f_{1}\left(x_{0}\right)\right|<\varepsilon$, hence $|f(x)-g(x)|<\varepsilon$ for all $x \in X$. Letting $\varepsilon \rightarrow 0$ shows that $g \in \mathfrak{F}$.

Corollary 5. Suppose that $C_{L / K}(X)$ separates the points of $X$ and that $I$ is a closed ideal of the K-algebra $C_{L / K}(X)$. Then there exists a closed invariant set $Y \subset X$ such that

$$
I=\left\{f \in C_{L / K}(X): f(Y)=\{0\}\right\} \text {. }
$$

Proof. Put $Y=\bigcap_{f \in r}\{x: f(x)=0\}$. Then $Y$ is a closed invariant subset of $X$. If $x_{1}, x_{2} \in X-Y$ and $x_{1} \neq x_{2}$, then there exists $f \in I$ such that $f\left(x_{1}\right) \neq 0$. If $f\left(x_{1}\right) \neq f\left(x_{2}\right)$, let $g$ be the constant function 1 , while if $f\left(x_{1}\right)=f\left(x_{2}\right)$, choose $g \in C_{L / K}(X)$ such that $g\left(x_{1}\right) \neq g\left(x_{2}\right)$. Then in either case the function $h=g f \in I$ and $h\left(x_{1}\right) \neq h\left(x_{2}\right)$. Now let $X_{1}$ be the topological space obtained from $X$ by identifying the points of $Y$, and let $p$ be the projection from $X$ to $X_{1}$. Then $p$ is continuous and if $x_{1}, x_{2} \in X$, we have $p\left(x_{1}\right)=p\left(x_{2}\right)$ if and only if either $x_{1}=x_{2}$ or $x_{1}, x_{2} \in Y$. A basis for the open neighborhoods of a point $x \in X_{1}$ is given by sets of the form $p(V)$, where $V$ is an open neighborhood of $p^{-1}(x)$ in $X$. If $\sigma \in \operatorname{Aut}\left(L^{\prime} / K^{\prime}\right)$ and $x \in X_{1}$, we define $\sigma x=p\left(\sigma p^{-1}(x)\right)$; this is well defined and yields a continuous map $(\sigma, x) \rightarrow \sigma x$ of Aut $\left(L^{\prime} / K^{\prime}\right) \times X_{1} \rightarrow X_{1}$. Denote by $C_{L / K}(X, Y)$ the $K$ algebra of $f \in C_{L / K}(X)$ which are constant on $Y$. If $f \in C_{L / K}(X, Y)$ define $p f \in C_{L / K}\left(X_{1}\right)$ by $(p f)(x)=f\left(p^{-1}(x)\right)$; this is well defined and yields a norm preserving isomorphism between $C_{L / K}(X, Y)$ and $C_{L / K}\left(X_{1}\right)$. Put $p I=\{p f: f \in I\} ; p I$ is a uniformly closed $K$-subalgebra which separates the points of $X_{1}$, and every function $p f \in p I$ vanishes on $p(Y)$; hence by Theorem $1, p I$ consists of all $f \in C_{L / K}\left(X_{1}\right)$ which vanish on $p(Y)$. Thus $I$ consists of all $f \in C_{L / K}(X)$ which vanish on $Y$. 
CoRollary 6. Suppose that $C_{L / K}(X)$ separates the points of $X$. Then the maximal ideals of the K-algebra $C_{L / K}(X)$ are precisely the sets of the form

$$
\left\{f \in C_{L / K}(X): f\left(x_{0}\right)=0\right\}
$$

where $x_{0} \in X$.

The following theorem permits the extension of Theorem 1 and its corollaries to certain subsets of $X$.

Theorem 7. Suppose $Y$ is a closed subset of $X$ and Aut $\left(L^{\prime} / K^{\prime}\right) Y=$ $X$. Then each continuous $K$-valued function $f$ on $Y$, satisfying $f(\sigma y)=\sigma f(y)$ whenever $\sigma \in \operatorname{Aut}\left(L^{\prime} / K^{\prime}\right)$ and both $y, \sigma y \in Y$, has a unique extension to a function $f_{1} \in C_{L / K}(X)$.

Proof. If $x \in X$, take $\sigma \in \operatorname{Aut}\left(L^{\prime} / K^{\prime}\right)$ such that $\sigma x \in Y$ and define $f_{1}(x)=\sigma^{-1} f(\sigma x)$. This definition is independent of the choice of $\sigma$, and $f_{1}$ is the unique extension of $f$ to $X$ which satisfies $f_{1}(\sigma x)=\sigma f_{1}(x)$ for all $x \in X$ and $\sigma \in \operatorname{Aut}\left(L^{\prime} / K^{\prime}\right)$. If $f_{1}$ were not continuous, there would exist a net $x_{i} \in X$ converging to $x_{0} \in X$ such that the net $f_{1}\left(x_{i}\right)$ would not converge to $f_{1}\left(x_{0}\right)$. Suppose that $x_{i}=\sigma_{\imath} y_{i}$ where $\sigma_{i} \in \operatorname{Aut}\left(L^{\prime} / K^{\prime}\right)$ and $y_{i} \in Y$. Since both Aut $\left(L^{\prime} / K^{\prime}\right)$ and $Y$ are compact, we may assume, by taking subnets if necessary, that both $\lim y_{i}=y_{0}$ and $\lim \sigma_{i}=\sigma_{0}$ exist. Then $\sigma_{0} y_{0}=x_{0}$ and

$$
\lim f_{1}\left(x_{i}\right)=\lim \sigma_{i} f\left(y_{i}\right)=\sigma_{0} f\left(y_{0}\right)=f_{1}\left(x_{0}\right) .
$$

This contradiction shows that $f_{1}$ is continuous.

We now consider a special case of the above results, which is of interest in applications. Suppose that $K$ is a finite algebraic extension of a field of $p$-adic numbers $Q_{p}$ and that $L=\widetilde{K}$ the algebraic closure of $K$. We take $X$ to be an invariant compact subset of $\widetilde{K}$ (the action of $\operatorname{Aut}(\widetilde{K} / K)$ is the usual one) and note that the map of $\operatorname{Aut}(\widetilde{K} / K) \times$ $X \rightarrow X$ given by $(\sigma, x) \rightarrow \sigma x$ is continuous. In fact given $\sigma_{0} \in \operatorname{Aut}(\widetilde{K} / K)$, $x_{0} \in X$, and $\varepsilon>0$, put

$$
H=\left\{\sigma \in \operatorname{Aut}(\widetilde{K} / K): \sigma x_{0}=\sigma_{0} x_{0}\right\}
$$

and

$$
N=\left\{x \in X:\left|x-x_{0}\right|<\varepsilon\right\} ;
$$

then both $H$ and $N$ are open and $H N=N$. We then obtain

THEOREM 8. Suppose $I$ is an ideal of $K[x]$; then the uniform closure of $I$ in $C_{\widetilde{K} / K}(X)$ is the set of functions $f \in C_{\widetilde{K} / K}(X)$ which vanish at every zero of $I$. 


\section{REFERENCES}

1. E. Artin, Theory of Algebraic Numbers, Göttingen, 1959.

2. I. Kaplansky, The Weierstrass Theorem in fields with valuations, Proc. Amer. Math. Soc. 1 (1950), 356-357.

Received July 11, 1966. The preparation of this paper was sponsored in part by N.S.F. Grant GP 5497.

University of CALIForNia at Los ANgeles 


\section{PACIFIC JOURNAL OF MATHEMATICS}

\section{EDITORS}

\section{H. SAMELSON}

Stanford University

Stanford, California

\author{
J. P. JANS \\ University of Washington \\ Seattle, Washington 98105
}

\section{J. DuGUNDJI}

University of Southern California

Los Angeles, California 90007

RichaRd ARENS

University of California

Los Angeles, California 90024

\section{ASSOCIATE EDITORS}

E. F. BECKENBACH
B. H. NeUManN

F. WOLF

K. YOSIDA

\section{SUPPORTING INSTITUTIONS}

UNIVERSITY OF BRITISH COLUMBIA

CALIFORNIA INSTITUTE OF TECHNOLOGY

UNIVERSITY OF CALIFORNIA

MONTANA STATE UNIVERSITY

UNIVERSITY OF NEVADA

NEW MEXICO STATE UNIVERSITY

OREGON STATE UNIVERSITY

UNIVERSITY OF OREGON

OSAKA UNIVERSITY

UNIVERSITY OF SOUTHERN CALIFORNIA
STANFORD UNIVERSITY

UNIVERSITY OF TOKYO

UNIVERSITY OF UTAH

WASHINGTON STATE UNIVERSITY

UNIVERSITY OF WASHINGTON

AMERICAN MATHEMATICAL SOCIETY

CHEVRON RESEARCH CORPORATION

TRW SYSTEMS

NAVAL ORDNANCE TEST STATION

Mathematical papers intended for publication in the Pacific Journal of Mathematics should be typewritten (double spaced). The first paragraph or two must be capable of being used separately as a synopsis of the entire paper. It should not contain references to the bibliography. Manuscripts may be sent to any one of the four editors. All other communications to the editors should be addressed to the managing editor, Richard Arens at the University of California, Los Angeles, California 90024.

50 reprints per author of each article are furnished free of charge; additional copies may be obtained at cost in multiples of 50 .

The Pacific Journal of Mathematics is published monthly. Effective with Volume 16 the price per volume ( 3 numbers) is $\$ 8.00$; single issues, $\$ 3.00$. Special price for current issues to individual faculty members of supporting institutions and to individual members of the American Mathematical Society: $\$ 4.00$ per volume; single issues $\$ 1.50$. Back numbers are available.

Subscriptions, orders for back numbers, and changes of address should be sent to Pacific Journal of Mathematics, 103 Highland Boulevard, Berkeley 8, California.

Printed at Kokusai Bunken Insatsusha (International Academic Printing Co., Ltd.), No. 6, 2-chome, Fujimi-cho, Chiyoda-ku, Tokyo, Japan.

PUBLISHED BY PACIFIC JOURNAL OF MATHEMATICS, A NON-PROFIT CORPORATION

The Supporting Institutions listed above contribute to the cost of publication of this Journal, but they are not owners or publishers and have no responsibility for its content or policies. 


\section{Pacific Journal of Mathematics}

\section{Vol. 21, No. $3 \quad$ BadMonth, 1967}

Richard Allen Askey, A transplantation theorem for Jacobi coefficients . . . 393

Raymond Balbes, Projective and injective distributive lattices .......... 405

Raymond Balbes and Alfred Horn, Order sums of distributive lattices . . . . 421

Donald Charles Benson, Nonconstant locally recurrent functions ........ 437

Allen Richard Bernstein, Invariant subspaces of polynomially compact operators on Banach space ............................... 445

Robert F. Brown, Fixed points and fibre ................... 465

David Geoffrey Cantor, On the Stone-Weierstrass approximation theorem for valued fields ................................ 473

James Walton England, Stability in topological dynamics .............. 479

Alessandro Figà-Talamanca and Daniel Rider, A theorem on random

Fourier series on noncommutative groups.................. 487

Sav Roman Harasymiv, A note of dilations in $L^{p} \ldots \ldots \ldots \ldots \ldots \ldots . \ldots 493$

J. G. Kalbfleisch, A uniqueness theorem for edge-chromatic graphs ....... 503

Richard Paul Kelisky and Theodore Joseph Rivlin, Iterates of Bernstein polynomials .................................... 511

D. G. Larman, On the union of two starshaped sets ............... 521

Henry B. Mann, Josephine Mitchell and Lowell Schoenfeld, Properties of differential forms in $n$ real variables ...................... 525

John W. Moon and Leo Moser, Generating oriented graphs by means of team comparisons .

Veikko Nevanlinna, A refinement of Selberg's asymptotic equation ...

Ulrich Oberst, Relative satellites and derived functors of functors with additive domain ..............................

John Vincent Ryff, On Muirhead's theorem...............

Carroll O. Wilde and Klaus G. Witz, Invariant means and the Stone-Čech compactification 